\title{
Mixed convective nanofluids over vertical channel having forward-facing step flow having a baffle
}

\author{
Omar. A. Hussein ${ }^{1}{ }^{*}$, Thamer Khalif Salem ${ }^{2}$ \\ ${ }^{1}$ Department of Mechanical Engineering, University of Tikrit, Tikrit, Iraq \\ ${ }^{2}$ School of Engineering, University of Ozyegin, Cekmekoy, Turkey
}

\author{
Index Terms \\ Forced and Natural Convection \\ Forward-Facing Step \\ Heat Transfer Enhancement \\ Baffle \\ Numerical Simulations
}

Received: 12 July 2016

Accepted: 15 August 2016

Published: 19 December 2016

\begin{abstract}
Numerical simulations of laminar flow complex for convective heat transfer through a 2D channel wall forward facing steps using different type of nanofluids having a baffle. The Finite Volume Method (FVM) solved by equations, momentum, continuity and energy equations and the SIMPLIC calculation plan is connected to look at the impacts of the baffle wall in flow, characteristics, and convective thermal enhancement. Four distinct sorts of nanofluids $\left[\mathrm{Al}_{2} \mathrm{O}_{3}, \mathrm{SiO}_{2}, \mathrm{CuO}\right.$, and $\mathrm{ZnO}$, with various volumes of particles in the scope of 0.01 to 0.04 scattered in the base liquid (water) are utilized. The effects of height $\mathrm{H}_{b}$ and width $\mathrm{Wb}$ of baffles, on Nusselt number variety are numerically simulated. The results demonstrate that $\mathrm{SiO}_{2}$ has the most astounding $\mathrm{Nu}$ contrasted and different nanofluids. The distribution district and $\mathrm{Nu}$ increment as the volume of nanoparticle increments and it diminishes as the particle's diameter increments.
\end{abstract}

\section{INTRODUCTION}

A circumstance where both the constrained and free convection effects are of equivalent request is called mixed or consolidated convection. The examination of Forced and natural convection flow over a vertical channel has got significant hypothetical and reasonable interest. The wonder of mixed convection happens in numerous specialized and mechanical issues, for example, electronic gadgets cooled by fans, atomic reactors cooled amid a crisis shutdown, a heat exchanger set in a low-speed environment, solar collectors and so on. A few creators have contemplated the issue of mixed convection in various surface geometries. Flow partition and reattachment because of sudden changes in geometry happen in numerous building applications that require heating or cooling. Fluid flow and thermal move in the field of these applications show twodimensional (2-D) conduct of the flow. Examiners have demonstrated the experimental and numerical values [1].
The way of the approaches to improve heat or mass transfer in the isolated districts is to utilize fluids. Solid nanoparticles are liquids that are stable suspensions of nanoparticles. These are nanometer particles suspended in liquids. In this way, it doesn't bring about an expansion in pressure gradient on the face of the step. Many researchers demonstrated that nanoparticles show upgraded heat transfer properties, for example, the thermal conductivity of the heat transfer fluids contrasted with liquid; see, for instance, [2], [3], [4] and [5].

[6] analyzed theory of enhancement of the heat exchange upgrade in flat channels by backward-facing step flow utilizing a baffle establishment. They noticed the lowest Nusselt number as the installation on wall was at distance $\mathrm{D}=0$. The results show the highest Nusselt number as the installation on wall was at distance $\mathrm{D}=0.2$. The most extreme increase in all things considering Nusselt number was around $190 \%$ for $150 \%$ for the downstream area and stepped wall of the base wall. A slight development of the

\footnotetext{
${ }^{*}$ Corresponding author: Omar. A. Hussein

${ }^{\dagger}$ Email: omar_assi2008@yahoo.com
} 
baffle position could bring about an exceptional change in the transfer qualities.

[7] researched numerically the upgrade flows in a two-dimensional channel of forced convection heat transfer with qualities of backward-facing step during the establishment of strong and opened baffles along the center of the channel divider. They found that the Nu was little for the state as $\emptyset_{t}=10^{\circ}$ less than that as $\emptyset_{t}=0^{\circ}$ in the stepped wall segment, however it was bigger at last district. In addition, the punishment of expansion in pressure drop was higher for that circumstance with baffle establishment.

The most critical conclusion, which has a vital importance to this research, is the way that the flow in a threedimensional channel of forced convection heat transfer by the backward-facing step has a solid three-dimensional conduct and the incorporation of this estimate ought to have assistance to give a few parts of the partition reattached to the area. Furthermore a superior comprehension of this phenomenon was noticed by [8]. Conducted forecast of the stream and warmth move in stepped wall with stunned balances were researched by [9] and [10].

The investigation of heat transfer and fluid flow over a forward-facing step in vertical nanofluid mixed convection as a part of two-dimensional uniform heat flux wall limit characteristics appears to have not been explored in this study.

Hence, this study manages distinctive sorts of nanofluids, for example, $\left[\mathrm{Al}_{2} \mathrm{O}_{3}, \mathrm{ZnO}, \mathrm{SiO}_{2}\right.$, and $\left.\mathrm{CuO}\right]$ with various nanoparticles' fractions. The effect of $\mathrm{Nu}$ is considered and noticed to delineate the effects of various parameters of nanofluids on flow.

\section{NUMERICAL PARAMETERS}

\section{A. Physical Model and Assumptions}

Two-dimensional nanofluids' flow in channel having forward-facing step having baffles is clearly shown in Figure 1 as a representation of mixed convective flow, along the center of the channel. A step height ( $\mathrm{S}$ ), with extension ratio is altered at $0.005 \mathrm{~m}$ and 2, separately. The upstream tallness of the duct $(\mathrm{h})$ and downstream height $(\mathrm{H})$ are $0.025 \mathrm{~m}$ and $0.01 \mathrm{~m}$, separately. The divider along the center of the step $\left(\mathrm{X}_{e}\right)$ is kept up at a parallel divider heat flux $\left(\mathrm{q}_{w}\right)$, the top wall structures the opposite other of the channel that is kept up at steady temperature equal to the inlet temperature $\left(\mathrm{T}_{o}\right)$. The top wall of the step $\left(\mathrm{X}_{i}\right)$ is adiabatic. The top wall is introduced a baffle of the forward-facing step designed as appeared in Figure 1. The baffle height and baffle width are kept as $0.01 \mathrm{~m}$ and $0.0075 \mathrm{~m}$. The length of along the channel area is $0.025 \mathrm{~m}$ upstream and $0.25 \mathrm{~m}$ downstream of the step extension individually.

Heat transfer flow at the channel wall passageway is thought to be hydrodynamically relentless and the completely created flow is accomplished at the end of the step, and the streamwise inclinations of amounts at the channel exit where set to be zero. Nanofluids at the channel inlet are thought to be hydrodynamically enduring and the completely created flow is accomplished at the end of the wall, with the slopes of all amounts at the exit.

This concentrate only manages laminar flows. The type of different nanoparticles with the liquid (i.e. water) is expected to have a heat balance and no other side happens. The liquid is thought to be Newtonian and uncompressible. Radiation heat exchange and thick dispersal term are ignored. The inner thermal generation is not directed in present results. Thickness is shifted and can be satisfactorily displayed by the Boussinesq estimate. GAMBIT 2.4.6 and FLUENT 6.3, business programings were utilized as a part of the present study to play out the simulations.

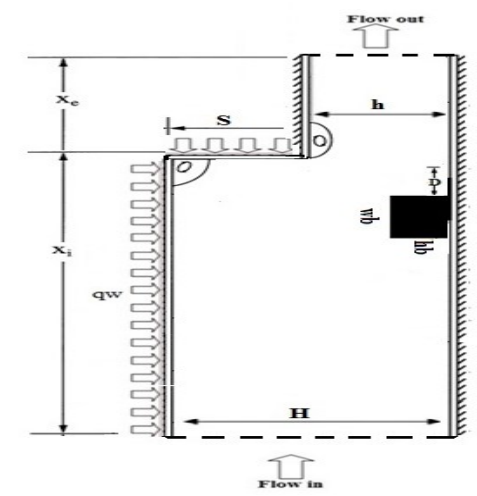

Fig. 1. Schematic diagram for space of FFS in a vertical channel with baffle

\section{B. Governing Equations}

To finish the Computational fluid elements' examination of forward-facing step, it's critical to set up mass and momentum equations for the governing. Utilizing the Boussinesq estimate and dismissing the type of effects of dissemination and compressibility, the dimensionless administering conditions for two-dimensional heat transfer flow incompressible can be composed as following forms [11]:

$$
\frac{\partial U}{\partial X}+\frac{\partial U}{\partial Y}=0
$$




$$
U \frac{\partial U}{\partial X}+V \frac{\partial U}{\partial Y}=-\frac{\partial p}{\partial x}+\frac{\mu_{n f}}{p_{n} u_{n f}} \frac{1}{R_{e}}\left(\frac{\partial^{2} U}{\partial X^{2}}+\frac{\partial^{2} U}{\partial Y^{2}}\right)
$$

$U \frac{\partial U}{\partial X}+V \frac{\partial U}{\partial Y}=-\frac{\partial p}{\partial x}+\frac{\mu_{n f}}{p_{n} u_{n f}} \frac{1}{R_{e}}\left(\frac{\partial^{2} U}{\partial X^{2}}+\frac{\partial^{2} U}{\partial Y^{2}}\right)+\frac{p(\beta)_{n f}}{p_{n f} \beta_{n f}} \frac{G r}{R e^{2}} \Theta$ (3)

The energy equation:

$$
U \frac{\partial \theta}{\partial X}+V \frac{\partial \theta}{\partial Y}=\frac{a_{n f}}{a_{f} \operatorname{RePr}}\left(\frac{\partial^{2} \theta}{\partial X^{2}}+\frac{\partial^{2} \theta}{\partial Y^{2}}\right)
$$

GRID INDEPENDENCE TEST RESULTS FOR NU AT RE $=500 \mathrm{E}$

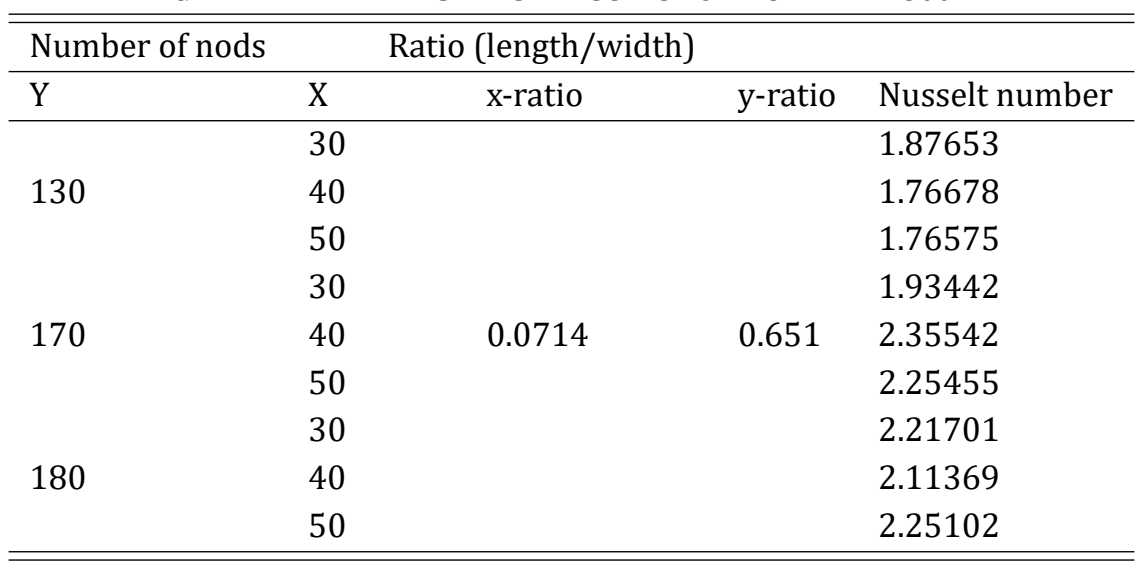

\section{A. Code Validation}

Code acceptance is exceptionally critical step in any numerical work so as to guarantee that the numerical code is approved with different pervious works and it is prepared for further runs. The present results acquired were compared and approved with the past studies and go about as a benchmark for the project. Then again, it is not imper-

\section{GRID INDEPENDENCE TEST}

In the present study, grid independence is utilized to direct the GIT by the effect of fluid flow of various nanofluin in backward-facing step. The grid independence test is led of nanofluid as working liquid. Grid densities of $180 \times 40$, $170 \times 30$, and $130 \times 30$, were chosen to play out a grid autonomy examined. Size of grid $170 \times 30$ affirms the independence test arrangement. It indicates under $3 \%$ contrast in $\mathrm{Nu}$ contrasted with other sizes of grid test appeared in table 1.

TABLE 1 


\section{B. Effective Physical Properties}

By utilizing Brownian movement of nanoparticles or Heat transfer features, the effective thermal effect can be acquired by utilizing the accompanying experimental relationship [14]:

$$
\begin{gathered}
\text { Viscosity }: \frac{\mu_{e f f}}{\mu_{f}}=\frac{1}{1-34.87\left(\frac{d_{p}}{d_{f}}\right)^{-0.3} \theta^{1.03}} \\
\text { Thediameterofliquidmolecule }: d_{f}=\left[\frac{6 M}{N \pi \rho_{b f}}\right]^{\frac{1}{3}}
\end{gathered}
$$

The density, $\rho_{n f}$ can be figured utilizing [13]:

$$
\rho_{n f}=(1-\theta) \rho_{f}+\theta \rho_{n p}
$$

At constant pressure can be calculated the heat capacity $\left(\rho c_{p}\right)_{n f}$ by using [13]:

$$
(\rho \beta)_{n f}=(1-\theta)\left(\rho c_{p}\right)_{f}\left(\theta \rho c_{p}\right)_{n p}
$$

C. To calculate the effect of thermal expansion $(\rho \beta)_{n f}$ by using [13]:

$$
(\rho \beta)_{n f}=(1-\theta)(\rho \beta)_{f}+\theta(\rho \beta)_{n p}
$$

Table 2 demonstrates the thermophysical properties for base fluid and distinctive nanofluids at $\mathrm{T}=300 \mathrm{~K}$ [13].

TABLE 2

GRID INDEPENDENCE TEST RESULTS FOR NU AT RE $=500 \mathrm{E}$

\begin{tabular}{llllll}
\hline \hline Thermophysical Properties & Pure Water & $\mathrm{Al}_{2} \mathrm{O}_{3}$ & $\mathrm{CuO}$ & $\mathrm{SiO} 2$ & $\mathrm{ZnO}$ \\
\hline Density, $\rho\left(\mathrm{kg} / \mathrm{m}^{3}\right)$ & 998.203 & 3970 & 6500 & 2200 & 5600 \\
Dynamic viscosity, $\mu\left(\mathrm{Ns} / \mathrm{m}^{2}\right)$ & $2.01 \times 10-3$ & - & - & - & - \\
Thermal conductivity, $\mathrm{k}(\mathrm{W} / \mathrm{m} . \mathrm{K})$ & 0.613 & 40 & 20 & 1.2 & 13 \\
Specific heat, cp $(\mathrm{J} / \mathrm{kg} . \mathrm{K})$ & 4182.2 & 765 & 535.6 & 703 & 495.2 \\
Coefficient of thermal expansion, $\beta(1 / \mathrm{K})$ & $2.06 \times 10^{-4}$ & $5.8 \times 10^{-6}$ & $4.3 \times 10^{-6}$ & $5.5 \times 10^{-6}$ & $4.3 \times 10^{-6}$ \\
\hline \hline
\end{tabular}

\section{RESULTS AND DISCUSSION}

The investigation for the laminar mixed convection heat transfer over two-dimensional vertical forward-facing steps area is assigned to exhibit the numerical results. The effects of various nanofluid sort, its focus and particles' distance across and baffle installation on the heat fields by vertical forward-facing step are investigated and examined.

\section{A. The Effect of Different Nanofluids' Parameters}

Different types of nanofluids which are $\mathrm{Al}_{2} \mathrm{O}_{3}, \mathrm{ZnO}$, $\mathrm{Si} O_{2}$ and $\mathrm{CuO}$ with base liquid are utilized. The effects of various nanoparticles on the thermal upgrade for every parameter ought to be settled, $\varphi=0.04$, and $\mathrm{d}_{p}=25 \mathrm{~nm}$, at $\operatorname{Re}$ $=500$ and $\mathrm{q}_{w}=500 \mathrm{~W} / \mathrm{m}^{2}$ along the downstream divider that are examined and exhibited. Figure 3 (a-b) demonstrates the $\mathrm{Nu}$ in saw at the downstream plate increments by expanding the separation stepped wall to a greatest quality close to the baffle wall at little separation heated plate of the reattachment region, it then abates gradually as the separation keeps on expanding in the streamwise bearing. This is because of the temperature distinction when the switched liquid is connected by the primary vortex due to lower temperature. Obviously nanofluid with $\mathrm{SiO}_{2}$ nanofluids has the best conduct in Nusselt number followed by other nanofluids separately. This is on account of interring the distribution regions where the nanofluids bring down thickness and thermal conductivity.

\section{B. Effect of Different Nanoparticles' Volume Fractions}

The volume concentration is really alluded to ratio of the volume of nanoparticles isolated by the mixture to all constituents before blending. Base fluid has zero volume of nanoparticles, for this segment, the nanoparticles' volume fraction in the scope of $0-4 \%$ at $\mathrm{D}=0.01, \mathrm{Re}=500$ and $\mathrm{q}_{w}$ $=500 \mathrm{~W} / \mathrm{m}_{2}$ was utilized. The outcomes show that expanding the volume fraction prompts improvement in the heat transfer move as delineated in Figure 4(a-b). This happens in light of the fact that expanding of nanofluids for nanoparticles' volume fraction prompts to increase the heat transfer enhancement of the liquid.

\section{The Effect of Baffle Height and Effect of Baffle Width}

In Figure 5b, the outcomes represent to increment 
Nusselt number after the nearness of the effect of baffle height with $\mathrm{D}=0.01, \mathrm{Re}=500$ and $\mathrm{q}=500 \mathrm{~W} / \mathrm{m}_{2}$ on the thermal improvement of forward-facing steps as appeared in Figure 5a. What's more an auxiliary distribution zone shows up into the region of the top wall. The baffle is lengthened to $\mathrm{H}_{b}=0.0075$. The primary flow of streamline is thickly stuffed than for ${ }_{b}=0.005$, Nu number further increments as it is around three once than the instance of $b=0.0075$. Also, the distribution zone on other side of the step is compacted and more grounded by the more drawn out baffle, but the distribution part on the base bottom in the bottom area extends. It is sensible to expect that even with a small baffle the thermal attributes can viably make strides. The $\mathrm{Nu}$ of $\mathrm{SiO}_{2}$ with $\mathrm{dp}=25 \mathrm{~nm}$, and $\varphi=4 \%$ for various baffle widths largest at $\mathrm{D}=0.01, \mathrm{q}_{w}=500 \mathrm{~W} / \mathrm{m}_{2}$ at $\mathrm{Re}=500$ distribution along the bottom plate divider has ap- peared in Figures 5(a-b). The Nusselt number increments as the baffle width increments because of addition in the distribution locale. The bulk temperature expands all the more quickly as the baffle width increments. As the confound width increments from $\mathrm{Wb}=0.01$ to $\mathrm{Wb}=0.02$, the distinctions in the non-generous heat in the area close to the forward- facing steps flow with the base wall. Correlation on the instances of $\mathrm{Wb}=0.01$ up to $\mathrm{Wb}=0.02$ uncovers the effects of widths on the greatest $\mathrm{Nu}$ that are unimportant. It can be seen that the $\mathrm{Nu}$ has the highest maximum peak inside distribution area as the baffle width diminishes until it achieves its ideal at the recirculation point. The effects of various baffle heights and widths on the streamlines have obviously appeared in Figure 6. Essential and optional distribution zones are shown in this figure. (a)

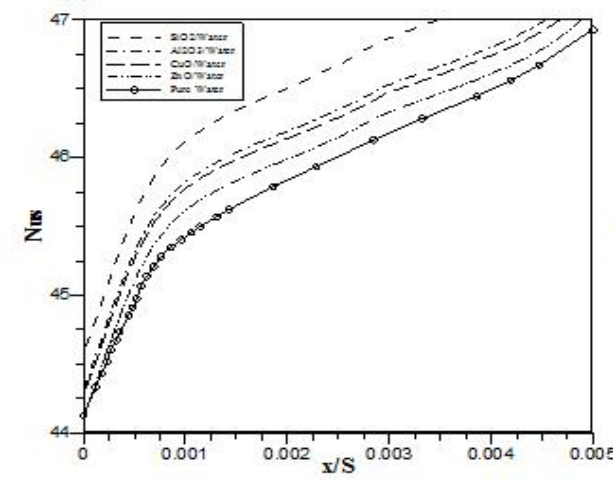

(b)

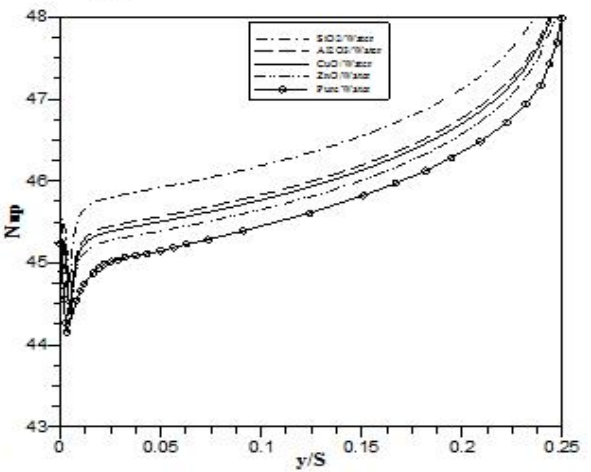

Fig. 3. The effect of different nanofluids at $\mathrm{Wb}=0, \mathrm{Hb}=0, \mathrm{Re}=500, \mathrm{~d}_{p}=25 \mathrm{~nm}, \varphi=4 \%$ and $\mathrm{q}_{w}=50 \mathrm{~W} / \mathrm{m}_{2}$ for, (a) stepped wall, (b) distribution along the center of the channel

(a)

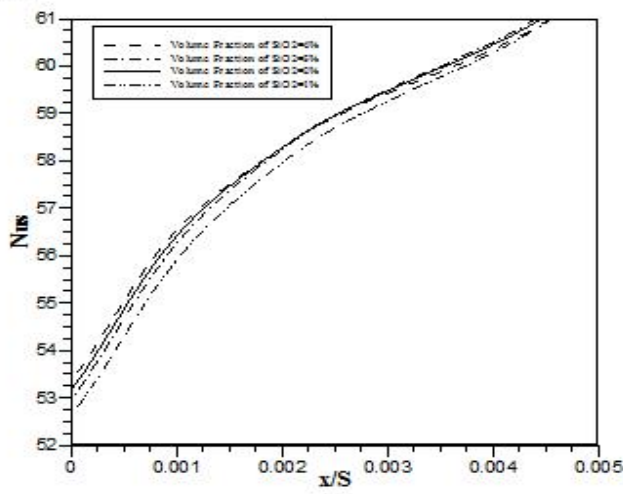

(b)

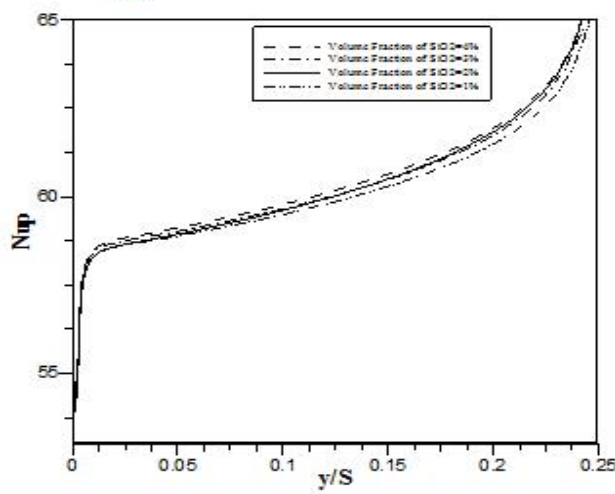

Fig. 4. The effect of different volume fractions at $\mathrm{Wb}=0, \mathrm{Hb}=0, \operatorname{Re}=500, \mathrm{~d}_{p}=25 \mathrm{~nm}, \varphi=4 \%$ and $\mathrm{q}_{w}=50 \mathrm{~W} / \mathrm{m}^{2}$ for, (a) stepped wall, (b) distribution along the center of the channel 
(a)

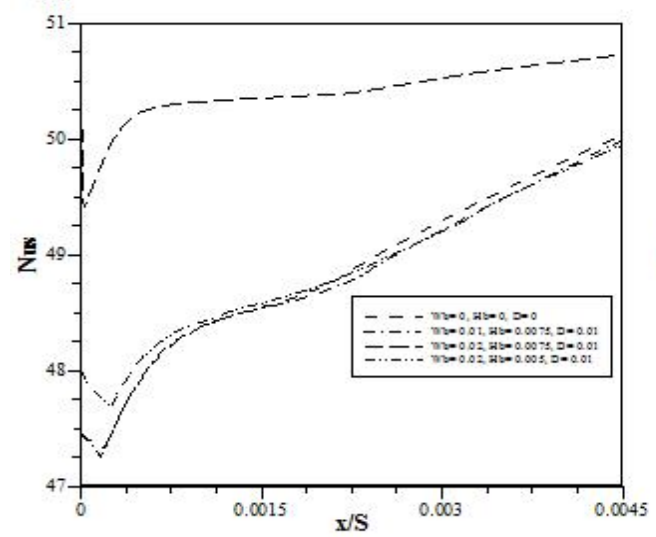

(b)

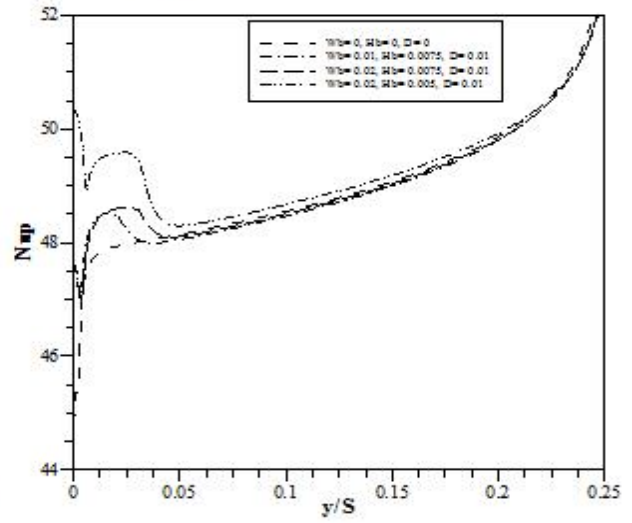

Fig. 5 . The effects of baffle height and width at $\operatorname{Re}=500, \mathrm{~d}_{p}=25 \mathrm{~nm}, \varphi=4 \%$ and $\mathrm{q}_{w}=50 \mathrm{~W} / \mathrm{m}^{2}$ for (a) stepped wall, (b) distribution along the center of the channel

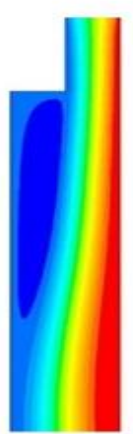

(a)

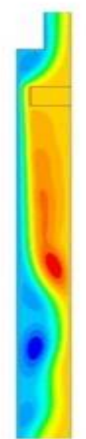

(b)

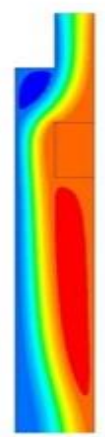

(c)

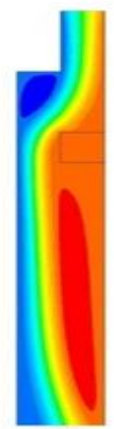

(d)

Fig. 6. Streamlines for four different baffle installation parameters at Re $=500$ (a) without baffle, (b) baffle height, (c,d) baffle width

\section{CONCLUSION}

Results of simulations for the investigation on laminar mixed convection over two-dimensional forward-facing steps set in a vertical channel by baffle at its divider were displayed. The accentuation is obtained on the thermal upgrade coming about because of different parameters, which incorporate the diverse sort of nanofluids, nanoparticles' volume fraction; the bottom plate of the forward-facing step was settled at parallel heat flux limit condition of baffle geometrical parameters. The overseeing equations were tackled using finite volume method with the SIMPLE calculation. The specific conclusions of this study are presented below:
1. The results demonstrate that $\mathrm{SiO}_{2}$ gives the most noteworthy $\mathrm{Nu}$ followed by $\mathrm{Al}_{2} \mathrm{O}_{3}, \mathrm{CuO}$, and $\mathrm{ZnO}$, separately, while base liquid is the least.

2. The Nu expanded with expanding the volume fraction of nanoparticles.

3. The effect of baffle width on thermal characteristic is unimportant.

\section{ACKNOWLEDGEMENTS}

Creators might want to acknowledge the academic fora for carrying out this study. Also, would like to thank the Istanbul Gonen Hotel, Istanbul, Turkey.

\section{REFERENCES}

[1] W. Aung, "An experimental study of laminar heat transfer downstream of back-step," Journal of Heat Transfer, vol. 105, no. 4, pp. 823-829. 1983. DOI: $10.1115 / 1.3245668$

[2] W. Daungthongsuk and S. Wongwises, "A critical review of convective heat transfer of nanofluids," Renewable and Sustainable Energy Reviews, vol. 11, no. 5, pp. 797-817, 2007. DOI: 10.1016/j.rser.2005.06.005 
[3] H. A. Mohammed, A. A. Al-aswadi, N. H. Shuaib and R. Saidur, "Mixed convective flows over backward-facing step in a vertical duct using various nanofluids-Buoyancy assisting case," Thermophys. Aeromech, Vol. 42, no. 1, pp. 1-30, 2012.

[4] H. A. Mohammed, A. A. Al-aswadi, N. H. Shuaib and R. Saidur, "Convective heat transfer and fluid flow study over a step using nanofluids: A review," Renewable and Sustainable Energy Reviews, vol. 15, no. 6, pp. 2921-2939, 2011. DOI: $10.1016 / j . r s e r .2011 .02 .019$

[5] X. Q. Wang and A. S. Mujumdar, 'Heat transfer characteristics of nanofluids: A review, " International Journal of Thermal Sciences, vol. 46, no. 1, pp. 1-19, 2007. DOI: 10.1016/j.ijthermalsci.2006.06.010

[6] Y. L. Tsay, T. Chang and J. Cheng, "Heat transfer enhancement of backward-facing step flow in a channel by using baffle installation on the channel wall," Acta Mechanica, vol. 174, no. 1, pp. 63-76, 2005. D0I: 10.1007/s00707-004-0147-5

[7] J. C. Cheng and Y. L. Tsay, "Effects of solid and slotted baffles on the convection characteristics of backward-facing step flow in a channel," Heat and Mass Transfer, vol. 42, no. 9, pp. 843-852, 2006. D0I: 10.1007/s00231-005-0051-0

[8] M. Habib, A. Mubarak, M. Sallak, E. A. A. Hadi and R. Affify, "Experimental investigation of heat transfer and flow over baffles of different heights," Journal of Heat Transfer, vol. 116, no. 2, pp. 363-368, 994. D0I: 10.1115/1.2911408

[9] K. Kelkar and S. Patankar, "Numerical prediction of flow and heat transfer in a parallel plate channel with staggered fins," Journal of Heat Transfer, vol. 109, no. 1, pp. 25-30. DOI: 10.1115/1.3248058

[10] B. Webb and S. Ramadhyani, "Conjugate heat transfer in a channel with staggered ribs," International Journal of Heat and Mass Transfer, vol. 28, no. 9, 1679-1687, 1985. DOI: 10.1016/0017-9310(85)90142-5

[11] B. Ghasemi and S. M. Aminossadati, "Brownian motion of nanoparticles in a triangular enclosure with natural convection," International Journal of Thermal Sciences, vol. 49, no. 6, pp. 931-940, 2010.

DOI: $10.1016 /$ j.ijthermalsci.2009.12.017

[12] J. Y. Nie, Chen and H. Hsieh, "Effects of a baffle on separated convection flow adjacent to backward-facing step," International Journal of Thermal Sciences, vol. 48, no. 3, pp. 618-625, 2009. DOI: 10.1016/j.ijthermalsci.2008.05.015

[13] J. D. Anderson, Computational Fluid Dynamics-The Basics with Applications. New York, NY: McGraw-Hill, 1995.

[14] R. S. Vajjha and D. K. Das, Experimental determination of thermal conductivity of three nanofluids and development of new correlations," International Journal of Heat and Mass Transfer, vol. 52, no. 21-22, pp. 4675-4682, 2009.

DOI: $10.1016 /$ j.ijheatmasstransfer.2009.06.027

— This article does not have any appendix. - 